\title{
O legado filosófico de John von Neumann
}

\author{
NICHOLAS A. VONNEUMAN
}

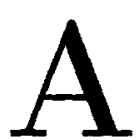

GRADEÇO A APRESENTAÇ̃̃o e o convite do Instituto de Matemática e Estatística e do Instituto de Estudos Avançados da niversidade de São Paulo, da Academia Brasileira de Ciências e da IBM do Brasil. É uma grande honra para mim esta oportunidade de poder participar num encontro de sua Universidade. Fico emocionado em saber que há tantas pessoas neste belo país interessadas em conhecer o lado humano do matemático e cientista John von Neumann, meu irmão.

Uma patente dos Estados Unidos de 1954-1957 [n ${ }^{\circ .} 2815488$ ], "Nonlinear capacitance or inductance, switching, amplifying, and memory organs," descreve um equipamento eletromagnético "which has both capacitance and inductance, at least one of these reactances having a non-linear characteristic. .." para produzir um sinal de saida em uma freqüência subharmônica. Naturalmente, o inventor não era um engenheiro eletrônico, mas $\operatorname{sim}$ um matemático, e essa foi a única patente de John. Ele sempre insistia em colocar à disposição da comunidade científica os resultados não-sigilosos de suas pesquisas, e se recusava a patentear, sendo esta a única exceção. Resultado de um relacionamento especial com a IBM, e produto de uma vasta análise de Fourier, ele demonstrou ser possível juntar dois sinais de ondas rápidas de tal forma que seu sub-harmônico formasse sinais distintos, propícios ao uso num computador, em velocidade aproximadamente mil vezes maior que aquelas empregadas na época. É uma entre as várias manifestações dos interesses diversificados e multidisciplinares e do escopo de trabalho de John, sempre empurrando as fronteiras da Matemática, e levando-as a territórios desconhecidos. Como, por exemplo, no caso do seu computador, o IAS 1952, a introdução de: sistema binário; programas armazenados; e flowchart, isto é, a separação do projeto da lógica e do projeto da engenharia, inicialmente descrito por ele em First draft of a report on the EDVAC em 1945, e incorporada pela primeira vez em seu computador, o IAS 1952 de Princeton.

\section{Goethe}

Seus interesses diversificados e multidisciplinares também se refletem em seu legado filosófico. Ele era positivista ou pragmático. Parecia 
respeitar especificamente um filósofo, Goethe. Afinal, Goethe era um filósofo, entre muitas outras profissões. $\mathrm{Na}$ escola, estudamos as duas partes de Fausto em profundidade, tanto no original como na tradução húngara. E desde então discutimos durante anos, relendo-o ocasionalmente. Existem, em particular, três passagens que chamaram a nossa atenção.

- Em primeiro lugar, as oito linhas finais da segunda parte: "Alles vergängliche ist nur ein Gleichnis..." Na minha tradução: "Todas as coisas transitórias senão como símbolo são lançadas / A insuficiência da Terra aqui se transforma em fato / $O$ indescritível aqui se faz / A Alma-Mulher para cima nos eleva." Existem várias interpretações para estas oito linhas. Mas relevante para os nossos propósitos era nossa especulação de que na abordagem global de Goethe havia, por trás de todas as manifestações da natureza, uma força unificadora que não conseguimos compreender integralmente aqui nesta terra, mas que podemos tentar explicá-la com os meios à nossa disposição. Foi com este espírito que John tentou satisfazer sua curiosidade e aprender os mistérios da natureza, com os meios à sua disposiçấo; a saber, fenômenos atômicos e subatômicos: por meio da mecânica quântica; previsão do tempo e fenômenos climáticos: por meio da meteorologia numérica; funçôes do sistema nervoso central: por meio de analogias com a lógica e a arquitetura dos computadores; genética e hereditariedade: através de sua teoria dos autômatos que se auto-replicam.

- A segunda passagem, na Parte I antes de partir em sua jornada, com relação à pergunta de Fausto, "aonde estamos indo", Mefistófeles responde: "O pequeno mundo e depois o grande veremos". De acordo com nossos estudos, associamos o mundo pequeno com a Parte I, que trata das emoções e paixões humanas básicas do homem solitário, e associamos o mundo grande com a Parte II, que trata das ambições intelectuais mais sofisticadas, já não solitárias, mas em conjunto com outros, como membros da sociedade. A discussão deste aspecto levou, então, à responsabilidade dos profissionais para com a sociedade, no escopo de suas respectivas profissões, levando em última instância às opiniốes de John sobre a responsabilidade social dos cientistas.

- Em terceiro lugar, o monólogo de Fausto na abertura da Primeira Parte: "No início era o Ato", e a declaração correspondente na Parte 
II: "A proeza é tudo, a glória, nada". Discutimos isto no contexto do valor redentor da ação, levando finalmente aos pontos de vista de John que enfatizam o valor redentor das aplicações práticas em sua profissão.

Basta de Goethe. Com uma ressalva, que John estava inteiramente familiarizado com as opiniões não muito lisonjeiras de Goethe sobre a Física Matemática e com a teoria da luz branca de Newton. Isto, entretanto, não afeta os aspectos filosóficos precedentes. Mas em prol do princípio do tempo igual, citarei também duas opiniões um tanto desairosas e indelicadas de Gothe sobre os cientistas: a primeira, a teoria da luz branca de Newton é errada. Por causa dela, a ciência sofrerá durante séculos; a segunda, os matemáticos são como os franceses. Insistem em traduzir tudo para seu próprio idioma, tornando-o, portanto, incompreensível. [Maximen und Reflexionen, Cotta 40 v. Ed. V. 39, UofPA VanPelt 838.G55]

\section{Positivismo}

Antes de tratar do positivismo de John, permitam-me mencionar sucintamente as origens de nossas ligações com o Brasil, que terão certa relevância ao explicar a atitude de .John com relação ao positivismo. John estava plenamente familiarizado com a história de todo o mundo, conhecimento este derivado especificamente da leitura pormenorizada da História Geral, em 44 volumes, do então famoso historiador Wilhelm Oncken (1838-1905). Alguns detalhes dela, ele então apresentava para discussões informais no círculo familiar. Assim ficamos conhecendo as razões históricas pelas quais o Brasil se tornou uma colônia portuguesa e, também, o passado positivista dos fundadores da República brasileira em 1889. Isto também se transformou na base de meu conhecimento sobre o Brasil quando, anos depois, participei, como advogado da Houdry Process Corporation, de negociações de contratos de licenças para os processos de tratamento catalítico de petróleo e desidrogenação de butano, com a assistência técnica à Petrobrás. Isto resultou em várias viagens de negócios ao Rio nas décadas de 60 e 70, para as quais tive de aprender rapidamente o idioma em que Camões chorou. $O$ francês de minha infância e, mais tarde, as aulas de latim clássico facilitaram e me prepararam muito bem para a sintaxe dos idiomas neolatinos. Passei a nutrir grande interesse por todos os outros aspectos da história do Brasil e, assim, desenvolvi um fundamento significativo para entender as miniconferências de John sobre o tema. 
No tocante ao positivismo de John, ele estava plenamente familiarizado com os três estágios do desenvolvimento do intelecto humano de Auguste Comte (teológico, metafísico e positivo); conhecia os antecedentes positivistas da inscrição Ordem e Progresso na bandeira brasileira, extraída do lema positivista: $O$ Amor por princípios, e a Ordem por base; o Progresso por fim. De qualquer forma, John adotou os princípios do positivismo, no sentido de regras confirmadas empiricamente ou na prática; não apenas os axiomas ou os rígidos preceitos estabelecidos $a$ priori, mas também as abordagens flexíveis ou oportunistas, e aplicações práticas.

\section{Responsabilidade social dos cientistas}

Dentre os mistérios da natureza, John estava também interessado nos mistérios da humanidade e dos seres humanos. Uma vez mais, não sendo capaz de resolvê-los, tentava simplesmente abordá-los. A presença de Thomas Mann em Princeton, por volta de 1939-1940, e suas palestras, entre elas aquela sobre The making of the magic mountain (A criação da montanha mágica), contribuíram para fazer reviver nossas vagas lembranças do herói, Hans Castorp, sonhando seu sonho de humanidade e de amor na cena da Neve, tentando formar uma concepção da humanidade do futuro, na realidade como alguém em busca de algo não inteiramente definido, nem inteiramente atinável, mas aquilo que ele, Hans Castorp, conseguiria fazer apenas na atmosfera intelectualmente estimulante da montanha encantada. Assim, Thomas Mann, em suas próprias declarações e ocasionalmente através da fala de seu herói, só conseguiu concluir que o próprio homem continua sendo um mistério e que toda a humanidade assume uma postura de reverência ante o mistério que é o homem; e, então, levantando a questão sobre se "deste festival universal da morte (a saber, a Primeira Guerra Mundial), será possível que - Amor um dia triunfe?" Bem, restou somente a esperança, mas èla não conflitava com a atitude de John e dos cientistas contemporâneos de que, na.Segunda Guerra Mundial, sua responsabilidade era para com a sociedade da qual faziam parte e a qual estava se defendendo contra uma ameaça sem precedentes de destruição e que a recusa em assumir esta responsabilidade os exporia à acusação de traição ou de deserção. E foi com este espírito que John declarou que a responsabilidade social dos cientistas cresceu de uma forma ampla e particular desde a pilha atômica de Chicago, em 1942, especialmente no campo das relações internacionais. Conseqüentemente, os cientistas já não são inteiramente livres para realizar sua pesquisa em torres de marfim isoladas, inteiramente desobrigados de relatar à sociedade os possíveis usos e conseqüências de 
suas descobertas, embora deixando a cargo de outros as decisões sobre a ação política. E que, conseqüentemente, a formação dos futuros cientistas não estará completa se limitada a questões técniço-profissionais, mas que deverá também incluir "história, direito, economia, governo, opinião pública etc, mas sem colocar em risco os fundamentos sobre os quais repousam e florescem as ciências." E foi também com este espírito que John formou suas opinióes geopolíticas, cuja substância era de que o mundo está se tornando pequeno demais para resolver disputas internacionais através do conflito armado. Citando a introdução editorial ao artigo que John escreveu para Fortune, em 1955, Can we survive technology (Poderemos sobreviver à tecnologia?), devemos reconhecer seu pessimismo construtivo, que não tolhe a criatividade. E, finalmente, as próprias palavras finais de John nesse artigo, no contexto do fato de a tecnologia e a ciência serem neutras embora potencialmente benéficas e perigosas: "os problemas do futuro da humanidade não podem ser resolvidos através de uma única receita, mas apenas de acordo com as medidas oportunistas no dia-a-dia e de acordo com as qualidades humanas necessárias: paciência, flexibilidade, inteligência."

\section{A mesa de jantar e a Matemática}

E agora de volta à juventude e à família. Em torno da mesa de jantar (que, à época, era também usada para um farto almoço com toda a família reunida), freqüentemente ouvíamos os comentários de nosso pai sobre sua profissão e suas atividades comerciais internacionais, como advogado e banqueiro que lidava com finanças; e as teorias subjacentes dele, puras ou abstratas, tais como a seleção de emprestadores ou de oportunidades de investimento. Isto geralmente levava a uma discussão geral sobre situações análogas em outras profissões, com relação às respectivas teorias subjacentes, puras ou abstratas, e as aplicações práticas resultantes, que podem ter influenciado as concepções posteriores de John com relação à Matemática e o seu desejo de não se perder nos campos abstratos, mas voltar-se, de tempos em tempos, às aplicações práticas.

Assim ouvíamos as especulações de John concernentes à natureza dupla da Matemática: abstrata ou pura versus aplicada ou empírica - em conexão com a última afirmar enfaticamente algumas das raízes mais significativas da Matemática terem sido motivadas por necessidades empíricas ou práticas - como, por exemplo, a geometria, o cálculo diferencial ou a resolução oportunista das controvérsias, no início do século, sobre os fundamentos da Matemática. 
Embora seu lar fosse a matemática pura ou abstrata, não se sentia satisfeito em lá permanecer e tentava penetrar em campos práticos, empíricos, sempre que um problema não podia ser solucionado com os métodos então existentes. Por exemplo: Ele não trabalhou em computadores para tornar mais fácil aos bancos a preparação de extratos financeiros, e sim para resolver problemas matemáticos nos quais havia necessidade de grandes velocidades, como nas equações diferenciais parciais não-lineares (aplicadas às ondas de choque, termodinâmica, previsão do tempo em termos globais em três camadas).

Foi também por esta razão que ele se declarou contrário a permitir que a Matemática se separasse de sua fonte empírica, que resultaria em endogamia abstrata e degeneração. Neste ponto, ele considerava que o único remédio seria o retorno rejuvenescedor à origem, a reinjeção de idéias mais ou menos empíricas.

\section{Papel e utilidade da Matemática}

Foi também com este espírito que ele discutiu o papel da Matemática $e$, mais especificamente, sua utilidade; se se deveria perseguir a ciência em geral ou a Matemática em especial por si só ou se em sua relação. com a sociedade; e aqui ele citou Schiller num diálogo fictício entre Arquimedes e um discípulo que expressava ao Mestre sua admiração pela ciência e seu desejo de ser iniciado naquela "ciência divina que acaba de salvar o Estado" (ajudando Siracusa contra o cerco do exército romano). Responde o Mestre: "a ciência é divina, mas era divina antes de ter ajudado o Estado e permanecerá divina independentemente de ter ou não ajudado o Estado". Ao que John acrescentou: "se a ciência não é mais divina por ajudar a sociedade, entâo não é menos divina por prejudicar a sociedade". E que "a ciência não se tornou menos divina simplesmente por ter certamente deixado de salvar o Estado quando Siracusa foi de fato tomada pelos romanos pouco depois disso".

$\mathrm{E}$, naturalmente, isto também se reflete sobre os pontos de vista de John com relação à responsabilidade dos cientistas: perseguir seus respectivos campos de pesquisa ou investigação, mas simplesmente advertindo a sociedade sobre os riscos potenciais envolvidos, com a proteção contra os riscos sendo, então, responsabilidade de outrem.

Agora, de volta à utilidade da Matemática. De acordo com John, a Matemática parece oferecer determinados padrões de objetividade que, até certo ponto, independem das questões emocionais ou morais, embora tais padrões não constituam padrões absolutos. Eles poderiam não ter 
validade absoluta para o mundo inteiro e, mesmo se válidos quando pronunciados, poderiam não permanecer válidos para sempre. $\mathrm{O}$ método da Matemática não é absoluto, não é algo revelado do alto. Pelo contrário, está sujeito a flutuações e sua avaliação muitas vezes se tinge de toques de conveniência, com critérios formalísticos e estéticos, com um sabor altamente oportunista.

E foi também com este espírito que ele avaliou a enorme importância da Matemática no pensamento, em uma área não tão precisa, na qual ela exibiu um grau necessário de flexibilidade que é muito difícil de se atingir num modo não-matemático. Por exemplo, a abordagem causal versus teleológica, como na mecânica clássica de Newton versus d'Alembert. Mas as duas são equivalentes. A história real derivada de uma delas é precisamente aquela encontrada a partir da outra. Tal percepção só pode ser garantida com a aptidão puramente matemática e com a flexibilidade das transformações e formulações matemáticas. Isto é um procedimento matemático e uma questão de conveniência, de gosto ou de oportunismo. Afinal, a Matemática é uma disciplina criada pelo homem.

Um outro exemplo de John. A teoria da probabilidade, um tratamento estritamente matemático para eventos indeterminados e fortuitos, que são incertos sob leis gerais. Mas, no modo matemático flexível, pode ser expressa com certeza. Evidentemente, não pela previsão daquilo que ocorrerá, mas afirmando-se que de $X$ tentativas quantas vezes será obtido um resultado positivo.

Suas analogias na mecânica quântica. O comportamento das partículas subatômicas não está sujeito às leis da mecânica clássica. Porém, somente a Matemática consegue expressar a combinação na qual a evolução da função de onda é previsível, mas na qual seu efeito sobre a realidade constitui apenas uma probabilidade. De fato, na mecânica quântica, apesar de se poder expressar as incógnitas posição e velocidade simultaneamente, não podemos determiná-las simultaneamente. Entretanto, é possível escolher uma delas para determinação, o que implica deterioração da informação sobre a outra.

Ainda outro exemplo. $\mathrm{O}$ procedimento e o método nas ciências são oportunistas. As ciências não explicam nem interpretam, mas principalmente criam modelos ou classificam. Os modelos descrevem fenômenos de uma área razoavelmente ampla. Devem satisfazer os critérios estéticos: devem ser simples. Material corretamente descrito deve ser heterogêneo, deve ser confirmado em áreas que não estavam na mente daquele que o 
inventou. Por exemplo, a mecânica quântica emergiu das dificuldades na espectroscopia, mas mostrou-se, desde então, capaz de descrever ou predizer outras coisas, na química ou na física do estado sólido. $O$ mesmo no tocante à mecânica newtoniana: foi introduzida para descrever o comportamento dos planetas; mais tarde, contudo, a teoria clássica da gravidade explicou os fenômenos tanto na escala humana quanto na planetária, com os maiores e os menores objetos: sua hipótese abrigou o universo e as menores partículas.

Aceitamos uma teoria que exiba maior adaptabilidade formal para uma extensão correta. Este é um critério formalista e estético com um toque altamente oportunista.

Mais sobre as opiniões de John sobre a utilidade da Matemática. Grandes áreas da Matemática têm sido muito úteis em termos práticos, ainda que às vezes com uma praticidade indireta. Algurmas áreas foram desenvolvidas para finalidades específicas embora, posteriormente, tenham se mostrado aplicáveis a outras. Por exemplo: as ciências físicas originaram-se da mecânica e as descobertas originais da mecânica desenvolveram-se a partir da astronomia, sem conexão com áreas de aplicações posteriores. Mas também existem campos que se desenvolveram sem praticamente qualquer relação com a utilidade, embora, mais tarde, tenham encontrado sua aplicação. Por exemplo, o campo das matrizes e dos operadores ou a geometria diferencial. E de tudo isto, a conclusão dele: é extremamente instrutivo estudar o papel da ciência e observar como o princípio de laissez-faire levou a estranhos e espantosos resultados.

\section{Mesa de jantar - continuação}

Meu pai também costumava discutir aspectos tecnológicos envolvidos em suas aplicações comerciais e industriais. Se se tratava de um empreendimento jornalístico, ele traria para casa amostras do tipo de fonte e a discussão seria sobre a imprensa escrita. Se o financiamento envolvia um empreendimento têxtil como, por exemplo, a Hungaria Jacquard Textile Weaving Factory, então a discussão estaria centrada no tear automático de Jacquard e em suas adaptações modernas. Entretanto, é possivel que tenha sido apenas uma estranha coincidência que, muito tempo depois, John viesse a se énvolver com os cartões perfurados da IBM.

As discussões também envolviam outros assuntos: política, ciência, teatro, arte e literatura, exibindo já neste estágio inicial a diversificada curiosidade e interesses de John em todas as direções. 
Por exemplo: as discussões da então nova arte da psicanálise, motivadas pela presença no círculo familiar de um parente próximo, Sándor Ferenci, um dos associados originais de Freud, que introduziu a psicanálise na Hungria. Isto, sem dúvida, afetou intensamente o interesse subseqüente de John na operação do cérebro e do sistema nervoso central.

\section{Outros exemplos:}

De nossos estudos, recordávamos, erroneamente talvez, que os receptores sensíveis à luz presentes na retina dos olhos realizavam exatamente a mesma função dos grãos de prata no filme fotonegativo, de tal forma que uma imagem de alta resolução, completa e inteiramente detalhada, é projetada e registrada na retina. John imediatamente fez objeção a isso, comentando que possivelmente as coisas não fossem tão simples assim, uma vez que, presumivelmente, a retina simplesmente coleta amostras; em seguida, chamou a atenção ao fato surpreendente de que, embora nos painéis criados pelo homem os feixes de fios saiam em direção à parte traseira, na retina eles se movem para frente num meio transparente antes de se curvar para trás e sair como o nervo óptico.

Estes interesses iniciais são novamente reconhecíveis em suas especulações subseqüentes sobre as funções e os circuitos do sistema nervoso central.

E agora, um exemplo precoce da dedução axiomática. Concurso num periódico de língua inglesa: Quem escreveu: "They know this well my baron and my men / Gascony, England, Normandy, Poitou / That I had never follower so low / Whom I would leave in prison to my gain. / I say this not as a reproach to them / But prisoner I am." ("Bem o sabem meus barões e meus homens / de Gasconha, Inglaterra, Normandia, Poitou / Que jamais teve seguidor tão baixo / A quem deixaria na prisão para meu proveito. / Não o digo como censura a eles / Mas prisioneiro eu sou.") Já que eu não sabia a resposta, perguntei-lhe e ele respondeu prontamente, sem hesitação: Ricardo Coração de Leão (Rei Ricardo I) Você conhecia este poema? - Não - Então como você identificou o poeta? - "Muito simples (ele disse), Gasconha, Inglaterra, Normandia e Poitou estiveram sob um mesmo domínio feudal apenas durante os primeiros tempos dos Plantagenetas e, partindo daí, foi muito fácil associar com as cruzadas de Ricardo e a sua prisão européia. Mas é claro (ele acrescentou) que isto é uma tradução, uma vez que os primeiros Plantagenetas falavam normando - o francês medieval."

Depois deste exemplo precoce da dedução axiomática, um da exibi- 
ção precoce da abordagem de um futuro estatístico. A catástrofe do Titanic permaneceu nas manchetes durante anos, particularmente depois que se tornam conhecidos os detalhes das investigações do Senado norteamericano e do Conselho Britânico do Comércio. Fiquei muito excitado com o argumento de que se apenas um dos vários fatores críticos contribuintes não tivesse ocorrido, a tragédia poderia ter sido evitada. John me assegurou que minha preocupação era ilógica. O que eu deveria dizer era: se um outro conjunto de circunstâncias aleatórias tivesse prevalecido... então algumas delas poderiam ter sido ainda piores. Exemplo: um dos fatores contribuintes significativos foi a ordem vinda da ponte, do Primeiro Oficial Murdoch: "hardastarboard - fullspeedastern" (fortemente à direita, rapidamente à popa), que no retrospecto e com percepção tardia poderia ser analisada e criticada. Mas troque-a por ventos altos ou uma tempestade e, então, nenhum dos barcos salva-vidas poderia ter sido abaixado! Isto não nos faria lembrar da linguagem de um futuro estatístico?

\section{Economia}

À mesa do jantar, a discussão muitas vezes centrava-se em bridge, xadrez, bacará, pôquer e outros jogos, comparando as regras fixas do xadrez com o blefe no pôquer, e analogias com competição em fatores desconhecidos ou imprevisíveis na vida comercial e em situações econômicas. Isto, supostamente, motivou o primeiro trabalho publicado de John, em 1928, sobre a teoria de Gesellschaftspiele. Mas a motivação final de entrar em maiores detalhes surgiu apenas depois de seu convívio com Oscar Morgenstern e sua publicação conjunta de Teoria dos jogos e o comportamento econômico. De qualquer forma, este é também um exemplo da singularidade de John de aplicar métodos matemáticos num campo que não era, até então, considerado propício para tais métodos.

\section{Preservação da herança cultural húngara}

À mesa de jantar, meu pai também falava freqüentemente sobre o significado da preservação de nossa herança cultural húngara. Alguns efeitos tardios disto sobre John:

No contexto da geometria não-euclidiana, John sempre mencionava antes o nome de Bolyai. Se outros se referiam somente a Gauss e a Lobachevsky como os fundadores que se libertaram das pré-concepções de espaço, John prontamente acrescentava Bolyai entre eles.

Na atmosfera social de Princeton dos 1930s-40s, John freqüentemente criticava nos outros a falta de conhecimento sobre as questões 
húngaras. Quando os outros descobriam com grande surpresa quantos húngaros famosos existiam, John reagia com grande seriedade: "É claro que sim, não somente os nomes famosos de Hollywood, como Paul Lukács ou Vilma Bánky, mas também Franz Liszt e Semmelweiss e, de fato, dois Bolyais e dois Eötvös-es!"

Talvez devamos também mencionar aqui o uso do título nobiliário da família, margittai, que John sempre usou. Sua matrícula na universidade de Zurique exibe seu nome como John Neumann vón Margitta. Somente mais tarde, seus editores alemães introduziram o conceito von Neumann.

\section{Pai e mãe}

Sempre que me referi à influência de meu pai, também deveria ter falado sobre a influência de minha mãe, que foi igualmente relevante, particularmente nos campos da arte e da literatura. Em meu livro, discuti em maior detalhe a influência que ela teve e, portanto, não gastarei mais tempo sobre isso neste momento. Contudo, gostaria de mencionar uma similaridade ou analogia adicional entre John e nosso pai, isto é, que o pai morreu (1929) também relativamente jovem (aos 59 anos), também de uma enfermidade que, na época, era considerada incurável. Borsszem Jankó (um semanário húngaro) publicou na época o seguinte obituário na forma de um verso de quatro linhas que, por analogia, se aplica tanto ao pai quanto a John: "margittai Neumann Miksa dr. / Egy munkás élet, sok szép akarat, / tegnapról mára im kettészakadt. / Alighogy heged támad ujra friss seb, / s a régi gárda kisebb, egyre kisebb". Em minha tradução: "Uma vida de trabalho árduo e muitos projetos louváveis agora chegaram subitamente a um fim. Velhas feridas nem bem cicatrizaram e novas aparecem; e a velha guarda se desvanece gradualmente". No caso do pai, em 1929, a velha guarda consistia dos líderes e executivos progressistas do renascimento comercial e industrial húngaro após a Primeira Guerra Mundial. No caso de John, também representava uma velha guarda que desaparecia gradualmente, de um outro ponto de vista. Mas uma nova guarda sempre segue à velha. No caso de John, ele deixou bem claro em suas falas e discussões quem ele considerava a nova guarda nos anos 1950s: as novas gerações de jovens de uma idade impressionável, que terão de aprender como viver juntos, independentemente de sua nacionalidade, religião ou ideologia. E foi nesse contexto que ele recomendou que as novas gerações deveriam selecionar campos da ciência e tecnologia em qualquer evento, pois a evolução é tão veloz que à época da graduação, ou ao iniciar o exercício da profissão, terão surgido campos inteiramente novos que poderiam não ter sido previstos no início de seus estudos. 


\section{Senso de humor}

À mesa de jantar ou em outro lugar qualquer, John gostava de contar anedotas com o seu divertido estilo cômico, não por pretender ser original, nem pelo divertimento, mas em prol da discussão e análise do significado oculto ou da mensagem implícita envolvidas numa anedota:

- O imperador e rei Franz Joseph visitava a região rural agrícola onde muitos da aristocracia húngara tinham grandes latifúndios e particularmente uma área onde a outrora famosa família Pállfy prosperou. Em todos os lugares ele era recebido por um pomposo comitê de recepção dos notáveis locais, chefiado pelo seu líder mais proeminente. Assim, no primeiro lugarejo, foi apresentado ao prefeito local, o conde Pállfy. No segundo, ao representante regional no Parlamento, conde Pállfy. No terceiro, ao presidente da Câmara do Comércio local, o conde Pállfy... e, finalmente, numa área onde a tradição era nomear um membro jovem dos Pállfys como Marechal do Fogo honorário, que aconteceu ser um menino de dez anos de idade, num uniforme de gala de um Marechal do Fogo, ele foi apresentado à Sua Majestade como o "Marechal do Fogo, o conde Pállfy". Sua Majestade olha surpreso ao rosto do jovem rapaz e diz: "So jung, und schon Pállfy!" (Tão jovem e já um Pállfy!). Contexto: ciência política e a alegada senilidade de Franz Joseph no momento da deflagração da Primeira Guerra Mundial.

- Cena de rua em Berlim, Primeira Guerra Mundial: um homem numa esquina gritando repetidamente: "O Kaiser é um idiota". Dois policiais surgem do nada e o detêm por alta traição. "Mas eu estava falando do Kaiser austríaco, não do nosso Kaiser". "Você nâo consegue nos enganar. Bem, sabemos quem é o idiota". Contexto: novamente a ciência política, mas agora vinculada às ambigüidades semânticas.

- Um pouco depois, a iniciativa de discutir temas científicos no contexto das anedotas foi oferecida através dos relatos do irmão Michael sobre seus estudos de engenharia. Por exemplo, em certa ocasião, Michael citou a revista anual da sua univerdade: "De uma palestra do famoso professor em engenharia estrutural: '... e os fatores de segurança devem ser selecionados de tal forma que, se de fato possível, a ponte não deverá desmoronar nem mesmo uma vez durante seus primeiros anos de uso' ". Isto naturalmente levou 
à discussão dos problemas financeiros e industriais dos efeitos colaterais resultantes da multiplicação das especificações básicas de segurança pelos fatores de, digamos, dois ou cinco ou mais, levando também John, o futuro estatístico, a comentar que sempre se pode, é claro, assegurar uma probabilidade de $100 \%$ através das fórmulas estatísticas, mas que, então, a dispersão dos intervalos e gastos a tornam proibitiva.

Existem muitos outros exemplos. Mas meu objetivo é simplesmente mostrar que este senso de humor reapareceu mais tarde na forma de um humor muito seco no pano de fundo das afirmações mais graves do cientista maduro:

- No contexto da comparação de organismos vivos com dispositivos criados pelo homem. "O organismo vivo, quando injuriado, consegue se restaurar. Mas quando aplainamos um dispositivo feito pelo homem com um martelo, então geralmente não há tal tendência de restauração."

- No contexto da previsão de tempo com computadores de alta velocidade: "Não é uma questão de fazê-lo com maior rapidez, mas fazê-lo de fato". Exemplo: Computações para uma previsão de tempo global de 30 dias pode consumir trinta dias. "Se levasse mais de 30 dias, então provavelmente não o faríamos".

- Durante os famosos, talvez infames, interrogatórios Oppenheimer do Conselho de Segurança Pessoal AEC, nos quais John apareceu como testemunha. $\mathrm{O}$ advogado do. Conselho apresentou a John uma pergunta baseada numa sitiação hipotética incrivelmente complicada, na qual alguém agia mal (insinuando Oppenheimer) e perguntou a John se ele teria agido da mesma maneira naquela situação (insinuando ele). Ele respondeu: “... o senhor me pede agora para admitir como hipótese que um outro alguém teria agido mal e me pergunta se eu teria agido da mesma maneira. Mas esta não é uma pergunta de quando você parou de bater em sua esposa?"

- No contexto dos problemas de manutenção com os dispositivos do tubo de vácuo, "é desejável que num dia que consiste de 24 horas, não devamos gastar na manutenção mais de 24 horas".

É claro que, no projeto do $I A S 1952$, isto foi levado muito a sério e resolvido pela operação de seus tubos de vácuo abaixo das especificações. 


\section{Conclusão}

Basta de anedotas e humor. E agora, na conclusão, gostaria de resumir algumas, e somente algumas, das mensagens deixadas por John como seu legado filosófico.

- O significado prático da Matemática como disciplina não é que ela nos possibilita resolver todas as questões com regras e rigor objetivamente lógicos, absolutos e duradouros; pelo contrário, ela nos permite manusear problemas com uma flexibilidade prática e oportunista. Por exemplo, as transformações matemáticas para conciliar abordagens causal versus teleológica (Newton versus d'Alembert) em relação à mecânica clássica; ou as teorias de Schrödinger, Heisenberg e outros sobre os envoltórios atômicos. Não existe nenhum conceito a priori de regras matemáticas. Afinal, a Matemática é uma disciplina criada pelo homem.

- A advertência de que "à medida que a disciplina Matemática se afasta de sua fonte empírica, ela pode levar à endogamia abstrata e ao risco de degeneração do sujeito matemático, isso até aquele ponto em que o remédio pode ser um retorno rejuvenescedor à origem, a reinjeção de idéias mais ou menos diretamente empíricas".

- A aerodinâmica, como ciência, é mais fácil de praticar e calcular se já tivermos uma experiência anterior em voar como passageiros ou pilotos; ou, falando em termos gerais, é mais fácil entender qualquer processo se já o tivermos usado, se já o tivermos assimilado de maneira instintiva, empírica. Isto se baseia em nossa memória dinamicamente associativa.

- A responsabilidade social dos cientistas. Os cientistas já não são inteiramente livres para realizar sua pesquisa em torres de marfim isoladas, inteiramente desobrigados de relatar à sociedade os possíveis usos e conseqüências de suas descobertas. Mas cabe aos outros a ação política ou as decisões estratégicas.

- Economia como ciência. Ele considerou a economia uma candidata às ciências naturais, embora ela ainda não tenha atingido tal estágio.

- Teoria Gestalt. Ele pensava principalmente no complelo-inteirototal, sem se perder nos pequenos detalhes. Contrariamente à armadilha comum de não ver o bosque a partir das árvores, só via o 
bosque e não dava atenção às árvores. De acordo com Paul Halmos, se ele precisasse de fatos, em lugar de buscar referências e ver o que os outros tinham feito, de novo, definia as noções básicas e desenvolvia a teoria até o ponto em que conseguisse usá-la. Outro exemplo: no curso dos interrogatórios de Oppenheimer, expressou suas opiniões várias vezes para deixar claro que os indivíduos deveriam ser julgados com base em sua personalidade total, e não com base em ações isoladas.

- A inclusão de traços de humor como um pano de fundo para as mensagens, não pela diversão, mas para facilitar a transmissão da mensagem, particularmente de uma mensagem desagradável.

- Mensagem às novas gerações: "inclua em seus estudos questões de ciência e tecnologia". A isto, gostaria de acrescentar minha própria mensagem: estudem outros idiomas, preferencialmente antes dos seis anos de idade.

- E o último, mas não menos importante: os pontos de vista geopolíticos de John. O mundo está se tornando pequeno demais para resolver disputas internacionais através do conflito armado. Remédio: paciência, flexibilidade, inteligência."

Bem, e isto é tudo, pelo menos por ora. Mas antes de realmente concluir, gostaria de especular sobre quais comentários John teria feito se estivesse aqui conosco, hoje... é claro que ele esteve conosco hoje... De qualquer maneira, creio que ele teria observado que não aconteceu muita coisa nos últimos 40 anos, em relação ao problema com o qual ele trabalhou há 40 anos, isto é, a compreensão e criação de modelos de sistemas extremamente complexos. Naquele tempo, ele estava preocupado com que, na busca de analogias entre computadores criados pelo homem e o cérebro humano, ou o sistema nervoso central, houvesse uma lacuna intransponível que não pudesse ser vencida no seu tempo.

Especificamente, o cérebro possui cerca de $10^{10}$ neurônios e dezenas, talvez centenas, de milhares de interconexões entre si e com o cerebelo, este último não estando diretamente envolvido com as funções motoras ou perceptivas, mas meramente (!) coordenando e associando outros segmentos do cérebro! A complexidade de tal rede não poderia sequer ser vislumbrada na época em que ele viveu. $\mathrm{E}$, de fato, ele costumava afirmar que o melhor modelo do cérebro que poderia ser criado era o próprio cérebro! Com o devido respeito às pesquisas atualmente em andamento 
sobre os sistemas complexos criados pelo homem, a ordem de magnitude de tais sistemas não os aproximou, nem mesmo um pouco, da complexidade do cérebro! De fato, com relação a isso, nada de novo aconteceu nos últimos 40 anos. Naturalmente não sabemos se John teria avançado sobre esta questão se pudesse ter continuado com suas especulações.

Isto é tudo. Obrigado por me ouvirem. Muito obrigado por sua atenção.

Nicholas A. Vonneuman é advogado na Pensilvânia, Estados Unidos.

Palestra feita pelo autor no encontro A obra e o legado de John von Neumann, organizado pelo Instituto de Estudos Avançados da USP e pela Academia Brásileira de Ciências no Instituto de Matemática e Estatística da USP em 14 de novembro de 1995. A apresentação foi parcialmente baseada no trabalho do autor John von Neumann as seen by his brother, (C)1987-1991, publicado por N.A.V.

Tradução de Vera de Paula Asssis. Revisão e edição do autor. O original em inglês - The philosophical legacy of John von Neumann - encontra-se à disposição do leitor no IEA-USP para eventual consulta. 